\title{
MamA essentiality in Mycobacterium smegmatis is explained by the presence of an apparent cognate restriction endonuclease
}

\author{
Samantha E. Randall ${ }^{1 \dagger}$, Maria Carla Martini ${ }^{1 \dagger}$, Ying Zhou' ${ }^{1}$ Samantha R. Joubran ${ }^{1}$ and Scarlet S. Shell ${ }^{1,2^{*}}$ (i)
}

\begin{abstract}
Objective: Restriction-Modification (R-M) systems are ubiquitous in bacteria and were considered for years as rudimentary immune systems that protect bacterial cells from foreign DNA. Currently, these R-M systems are recognized as important players in global gene expression and other cellular processes such us virulence and evolution of genomes. Here, we report the role of the unique DNA methyltransferase in Mycobacterium smegmatis, which shows a moderate degree of sequence similarity to MamA, a previously characterized methyltransferase that affects gene expression in Mycobacterium tuberculosis and is important for survival under hypoxic conditions.

Results: We found that depletion of mamA levels impairs growth and produces elongated cell bodies. Microscopy revealed irregular septation and unevenly distributed DNA, with large areas devoid of DNA and small DNA-free cells. Deletion of MSMEG_3214, a predicted endonuclease-encoding gene co-transcribed with mamA, restored the WT growth phenotype in a mamA-depleted background. Our results suggest that the mamA-depletion phenotype can be explained by DNA cleavage by the apparent cognate restriction endonuclease MSMEG_3214. In addition, in silico analysis predicts that both MamA methyltransferase and MSMEG_3214 endonuclease recognize the same palindromic DNA sequence. We propose that MamA and MSMEG_3214 constitute a previously undescribed R-M system in $M$. smegmatis.
\end{abstract}

Keywords: Mycobacterium smegmatis, MamA, Restriction-Modification system, DNA methylation, Methyltransferase

\section{Introduction}

The primary role of bacterial Restriction-Modification (R-M) systems has typically been viewed as protection from foreign DNA, such as plasmids and phages. However, further work revealed these systems can have other important functions, including regulation of gene

\footnotetext{
*Correspondence: sshell@wpi.edu

†'Samantha E. Randall and Maria Carla Martini contributed equally to this work

${ }^{1}$ Department of Biology \& Biotechnology, Worcester Polytechnic Institute, Worcester, MA, USA

Full list of author information is available at the end of the article
}

expression and promoting bacterial evolution by enhancing DNA recombination [1-4].

To date, no complete R-M systems have been defined in M. tuberculosis, the causative agent of tuberculosis, or in its non-pathogenic relative M. smegmatis, a model system widely used to study the basic biology of $M$. tuberculosis. We previously identified and characterized one of the three predicted DNA methyltransferases in $M$. tuberculosis, MamA [5], which is non-essential for M. tuberculosis survival in vitro and during infection [6-8]. We and others showed that MamA is an adenine methyltransferase that affects expression of a number of genes in M. tuberculosis during log phase growth and promotes survival

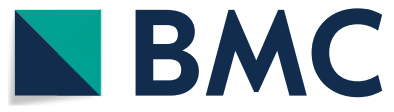

(c) The Author(s) 2020. This article is licensed under a Creative Commons Attribution 4.0 International License, which permits use, sharing, adaptation, distribution and reproduction in any medium or format, as long as you give appropriate credit to the original author(s) and the source, provide a link to the Creative Commons licence, and indicate if changes were made. The images or other third party material in this article are included in the article's Creative Commons licence, unless indicated otherwise in a credit line to the material. If material is not included in the article's Creative Commons licence and your intended use is not permitted by statutory regulation or exceeds the permitted use, you will need to obtain permission directly from the copyright holder. To view a copy of this licence, visit http://creativeco mmons.org/licenses/by/4.0/. The Creative Commons Public Domain Dedication waiver (http://creativecommons.org/publicdomain/ zero/1.0/) applies to the data made available in this article, unless otherwise stated in a credit line to the data. 
under hypoxic conditions [5, 9]. However, the function of its homolog in M. smegmatis has not been shown. Unlike in $M$. tuberculosis, the mamA homolog in M. smegmatis (MSMEG_3213) is essential for in vitro growth. Several attempts in our laboratory failed to obtain mamA knockouts, which is consistent with recently reported Tn-seq data [10]. Here, we demonstrate that mamA and its cotranscribed restriction endonuclease form a previously undescribed R-M system in M. smegmatis.

\section{Main text}

\section{Materials and methods}

\section{Strains and growth conditions}

M. smegmatis $\mathrm{mc}^{2} 155$ strains were grown in Middlebrook 7H9 media (Sigma) supplemented with ADC [11]. When needed, Middlebrook 7H10 solid media (Sigma) supplemented with ADC was used. Cells were cultured at $37{ }^{\circ} \mathrm{C}$ at $200 \mathrm{rpm}$. When required, $50 \mu \mathrm{g} / \mathrm{mL}$ kanamycin or $250 \mu \mathrm{g} / \mathrm{mL}$ hygromycin were added.

Inducible mamA knockdown (KD) was achieved by modification of the L5-integrating CRISPRi plasmid pJR962 [11], which contains a dCas9 and a non-targeting sgRNA. The non-targeting sgRNA was replaced with 20 nts of the mamA (MSMEG_3213) coding sequence (MSMEG_3213 coordinates: 103-122). The rescue plasmid containing full $m a m A$ gene sequence with two point mutations at nucleotides $96(\mathrm{C} \rightarrow \mathrm{G})$ and $99(\mathrm{C} \rightarrow \mathrm{T})$ of the coding sequence was done in the pSS047 backbone, which integrates at the Giles $a t t B$ site and is derived from pGH1000A [12] using the native mamA promoter and 5' UTR (242 nt upstream of the coding sequence: 42 nt known UTR and $200 \mathrm{nt}$ predicted promoter). The MSMEG_3214 knockout was obtained by recombineering [13] in which nucleotides 29-993 of the annotated MSMEG_3214 coding sequence were replaced by a hygromycin resistance cassette.

\section{Growth curve determination}

mamA KD and overexpressing strains were grown to log phase and diluted in $7 \mathrm{H} 9$ media to an $\mathrm{OD}_{600 \mathrm{~nm}}$ of 0.01 or 0.001 and $200 \mu \mathrm{L}$ aliquots were placed in 96 well plates. Growth was determined by automated OD recording in an Epoch 2 plate reader (BioTek). Samples were incubated at $37^{\circ} \mathrm{C}$ with shaking using a single orbital pattern at $807 \mathrm{cpm}$. $\mathrm{OD}_{600 \mathrm{~nm}}$ was measured every $10 \mathrm{~min}$ for $24 \mathrm{~h}$. When indicated, Anhydrotetracycline (ATc) was added to a final concentration of $200 \mathrm{ng} / \mathrm{mL}$ for induction of dCas9 and sgRNA expression.

\section{Viability assay}

Log-phase cultures were normalized and diluted to an $\mathrm{OD}_{600 \mathrm{~nm}}$ of 0.01 as described above. When indicated, ATc was added. For CFU determination, samples were taken at the indicated times and serial dilutions were plated on antibiotic-free $7 \mathrm{H} 10$ plates.

\section{Brightfield and fluorescence microscopy}

Cultures were grown in the presence or absence of ATc to an $\mathrm{OD}_{600 \mathrm{~nm}}$ of $0.05-0.15$. Aliquots of $1.5 \mathrm{~mL}$ were pelleted and the supernatant removed. Pellets were resuspended in $500 \mu \mathrm{L}$ of $2 \%$ paraformaldehyde in PBS and incubated at room temperature for $30 \mathrm{~min}$. Cells were then pelleted and resuspended in $900 \mu \mathrm{L}$ of $\mathrm{PBS}+0.1 \%$ Tween 20 (PBS-T). This was repeated for a total of two washes. Pellets were finally resuspended in $50 \mu \mathrm{L}$ of PBS-T. Fixed cells were then stained with SYTO 24 and/or FM 4-64FX (both ThermoFisher). For DNA visualization, cells were stained in $2 \mu \mathrm{M}$ SYTO 24 for $10 \mathrm{~min}$ before washing and resuspending in $50 \mu \mathrm{L}$ of PBS-T. For membrane staining, cells were stained with $8 \mu \mathrm{L}$ of $100 \mu \mathrm{g} / \mathrm{mL}$ FM 4-64FX for 10 min before washing twice with PBS-T and resuspending in $100 \mu \mathrm{L}$ of PBS-T. $2 \mu \mathrm{L}$ of cells were mixed with $6 \mu \mathrm{L}$ of mounting media ( $20 \mathrm{mM}$ Tris $\mathrm{pH} 8,0.5 \% \mathrm{~N}$-propyl gallate, and $50 \%$ glycerol), and pipetted onto an agar pad on a slide. Cells were viewed using a Zeiss AX10 microscope with ApoTome and a 40X oil objective.

Analysis of microscopy photos was performed using Image (NIH) and GraphPad Prism 8 software. Statistical analysis was performed using one-way ANOVA, Dunn's multiple comparison tests, and non-parametric tests.

\section{Results}

\section{Depletion of MamA impairs growth and reduces viability in M. smegmatis}

We generated an ATc-inducible mamA KD strain and a control with a non-specific CRISPRi construct containing an sgRNA that does not target the M. smegmatis genome [11]. We first evaluated growth of mamA KD in 7H9 medium. Consistent with the idea that $m a m A$ is essential for growth, we observed a slowing of growth followed by growth cessation in the mamA KD strain after $10 \mathrm{~h}$ incubation in presence of ATc (Fig. 1a).

We previously showed that mamA is co-transcribed with its downstream gene, MSMEG_3214 [14]. As CRISPRi represses transcription of co-transcribed genes, we constructed a rescue vector expressing a second copy of mamA with two synonymous point mutations that disrupt the PAM adjacent to the sgRNA binding site and thus prevent dCas9 binding. This vector was integrated into the genome of $M$. smegmatis that also contained the mamA KD construct. We observed that, in presence of ATc, the rescued strain recovered the ability to grow normally (Fig. 1a), confirming that the growth cessation 


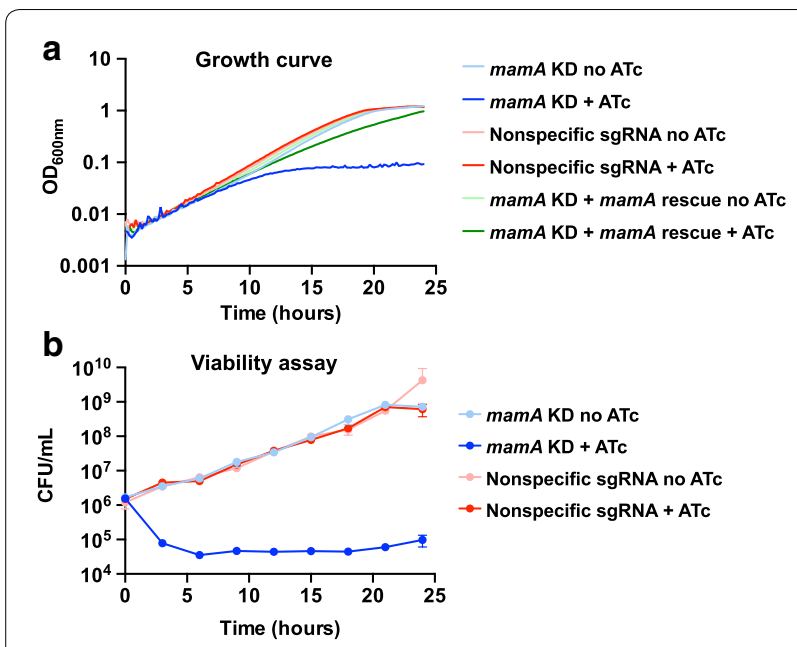

Fig. 1 mamA depletion causes growth cessation in M. smegmatis. a Strains with depleted mamA (mamA KD), nonspecific CRISPRi control with a sgRNA sequence that does not target any specific part of M. smegmatis genome (Nonspecific sgRNA), or a rescue vector containing a synonymous mamA mutant that is not bound by dCas 9 ( $m a m A$ Rescue) were incubated in $7 \mathrm{H} 9$ in presence $(+)$ or absence of ATc to activate or not the CRISPRi knockdown system, respectively. Three biological replicates of mamA KD, four biological replicates of mamA Rescue, and two technical replicates of each were used and values were averaged. $\mathbf{b}$ The strains were grown in $7 \mathrm{H} 9$ and CFUs were calculated at different timepoints

observed in the mamA KD strain is not attributable to depletion of the downstream gene.

To determine whether the cells were viable after mamA KD, we calculated CFUs at different timepoints (Fig. 1b). Strikingly, the mamA depleted cultures displayed a nearly 100 -fold decrease in CFUs within the first $6 \mathrm{~h}$ of ATc addition, and the number of viable cells remained similar during the experiment, suggesting that the depletion of $m a m A$ results in cell death.

\section{MamA depletion results in cell elongation and asymmetric DNA distribution}

Considering the growth defect in mamA depleted cultures, we sought to investigate the impact of mamA KD on cell morphology. Cultures were grown in presence or absence of ATc for $12 \mathrm{~h}$ and viewed by DIC microscopy (Fig. 2a). mamA depleted cells (panel D) were elongated compared to those of the control cells. We measured cell lengths in a blinded analysis for each strain and condition (Fig. 2b). While control strains and treatments had an average length approximately $5.7 \mu \mathrm{m}$, mamA KD cells exhibited an average length of $12.8 \mu \mathrm{m}$. mamA KD cell lengths also had a larger coefficient of variation, 31.6\%, compared to control cells, $21.6 \%$. Reduction of $m a m A$ levels therefore causes filamentation in M. smegmatis.
We further determined DNA content and localization by fluorescence microscopy using the DNA stain SYTO 24 (Fig. 2c). Control cells showed fairly even distribution of DNA throughout the cell length, while mamA depleted cells displayed highly uneven distributions of DNA, with fluorescence often focused around the midpoint of the cell leaving large areas devoid of DNA. To quantify the difference in DNA distribution, we calculated DNA occupancy for cells as in [15]. Cells lengths and lengths of fluorescent zones were measured in ImageJ in a blinded analysis. mamA depleted cells had significantly lower DNA occupancy than control cells, with averages of $49.1 \%$ occupancy, and $79.3 \%$ occupancy, respectively (Fig. 2d).

\section{MamA depleted cells have three major phenotypes}

To determine if elongated mamA KD cells had septa (chaining phenotype) or not (filamenting phenotype), mamA KD cells were grown in presence of ATc for $12 \mathrm{~h}$ and double stained with the membrane stain FM 4-64FX and the DNA stain SYTO 24. We noted three distinct categories of mamA KD cells (Fig. 3a). The first were long cells with evidence of septation. The number of septa per cell varied from one to four within this category. Most of the chaining cells had DNA located within each segment; however, many had segments at the poles that did not appear to contain DNA. The second category, long cells without an obvious septum, were grouped by the appearance of cell filamentation. These cells tended to have DNA localized near the middle of the cell with large portions of the cells near the poles that were apparently devoid of DNA. The third category were small cells, which were similar in size or smaller than control cells, that had no evidence of DNA. These data show that mamA depletion leads to irregular cell division and DNA distribution.

\section{MamA appears to be part of an R-M system in M. smegmatis}

Considering the essentiality of mamA in M. smegmatis, we suspected that this methylase could be part of an $\mathrm{R}-\mathrm{M}$ system, and that lack of MamA is toxic because an active restriction endonuclease recognizing the same sequence cleaves the genome when unmethylated. In addition, it has been observed that disturbance of R-M systems increases cell filamentation in bacteria [16-18], supporting the idea that the unbalance in the R-M system could be the reason for the mamA KD phenotype. We previously found that $m a m A$ is co-transcribed with the downstream gene, MSMEG_3214 [14]. A BLASTp of MamA and MSMEG_3214 sequences against REBASE, a comprehensive database of information about restriction enzymes and DNA methyltransferases involved in restriction-modification [19], revealed that these genes 
a

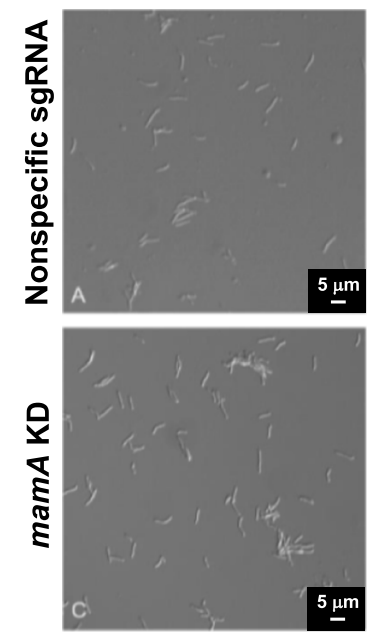

No ATc
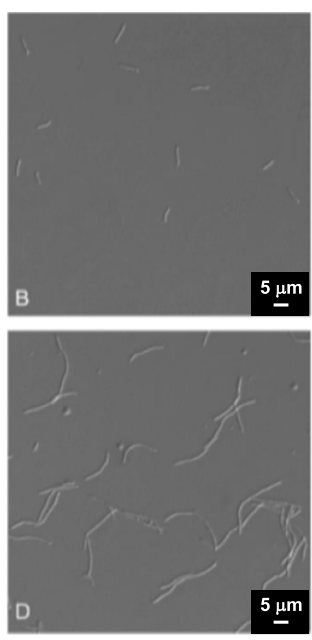

+ATc

b

\section{Cell length distribution}

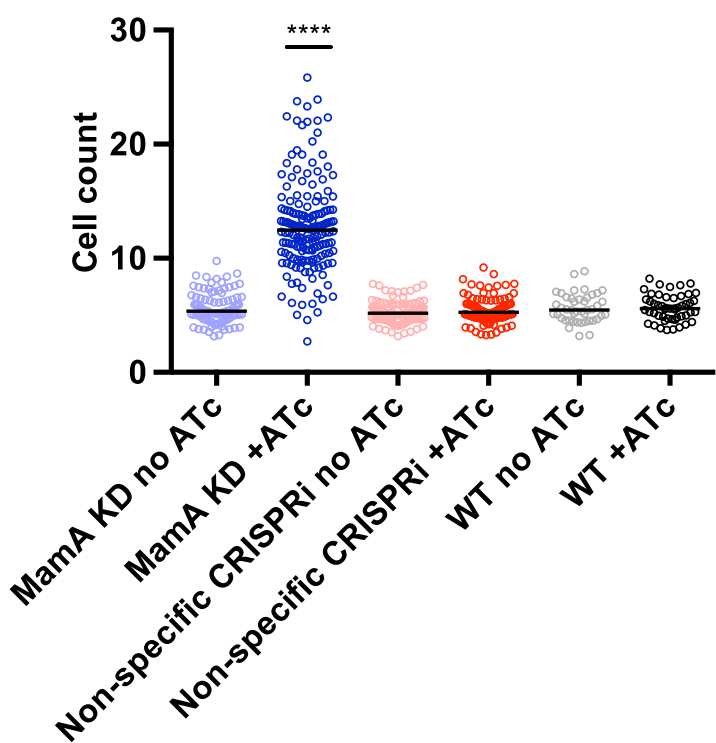

c
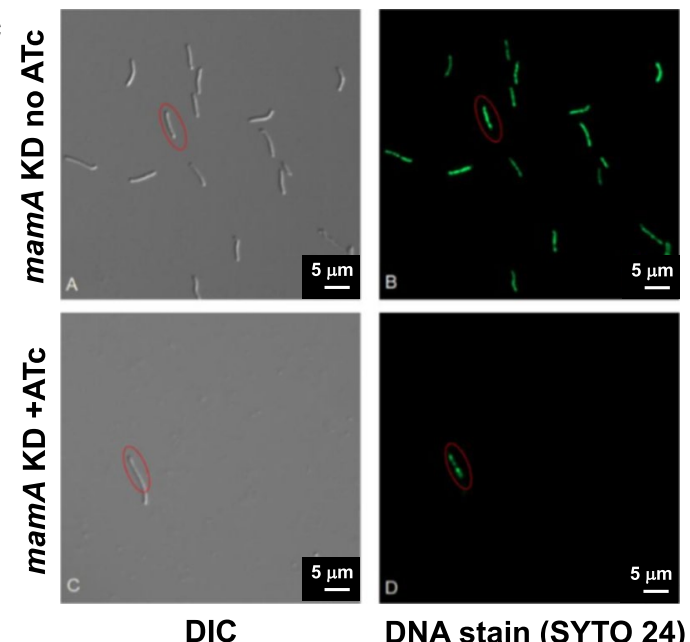

DNA stain (SYTO 24) d DNA occupation

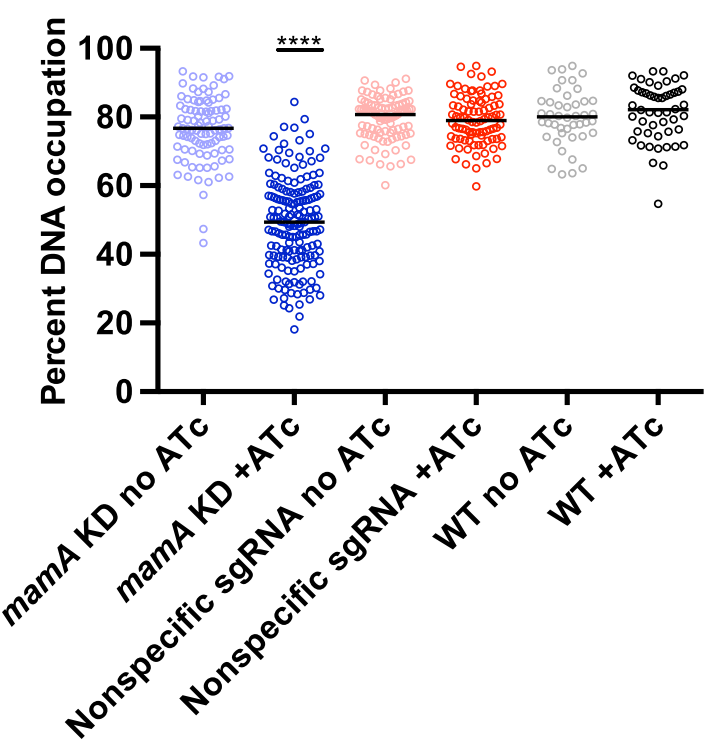

Fig. 2 Lowering mamA levels leads to cell filamentation and asymmetric DNA distribution. a DIC Microscopy showing WT (upper panels and mamA KD no ATc) and mamA depleted (mamA KD +ATc) phenotypes. b Cell length distribution determined by microscopy and analyzed with ImageJ software. c DIC microscopy and DNA staining with SYTO 24 in mamA depleted (+ ATc) and non-depleted (no ATc) cells. d Quantification of DNA occupation observed in SYTO 24-stained cells. Percent DNA occupation was calculated by dividing length of DNA fluorescence by cell length. ${ }^{* * * *} p<0.0001$ Kruskal-Wallis followed by Dunn's multiple comparisons test

encode for a predicted Type II N4-cytosine or N6-adenine DNA methyltransferase, and a predicted Type II restriction enzyme, annotated as M.Msms1ORF2534P and Msms1ORF2534P, respectively, and both are predicted to recognize the same palindromic sequence, CTCGAG. Thus, we reasoned that, if MSMEG_3214 is the cognate restriction endonuclease of MamA and the phenotype observed in depleted MamA cells is due to self-DNA cleavage, a knockout of MSMEG_3214 in the
MamA-depleted background should restore the WT phenotype. We generated an MSMEG_3214 deletion strain containing the mamA CRISPRi construct and evaluated its growth in the presence and absence of ATc (Fig. 3b). In the absence of MSMEG_3214, mamA KD does not affect growth, supporting the hypothesis that MamA and MSMEG_3214 are part of an active R-M system in $M$. smegmatis. 
a
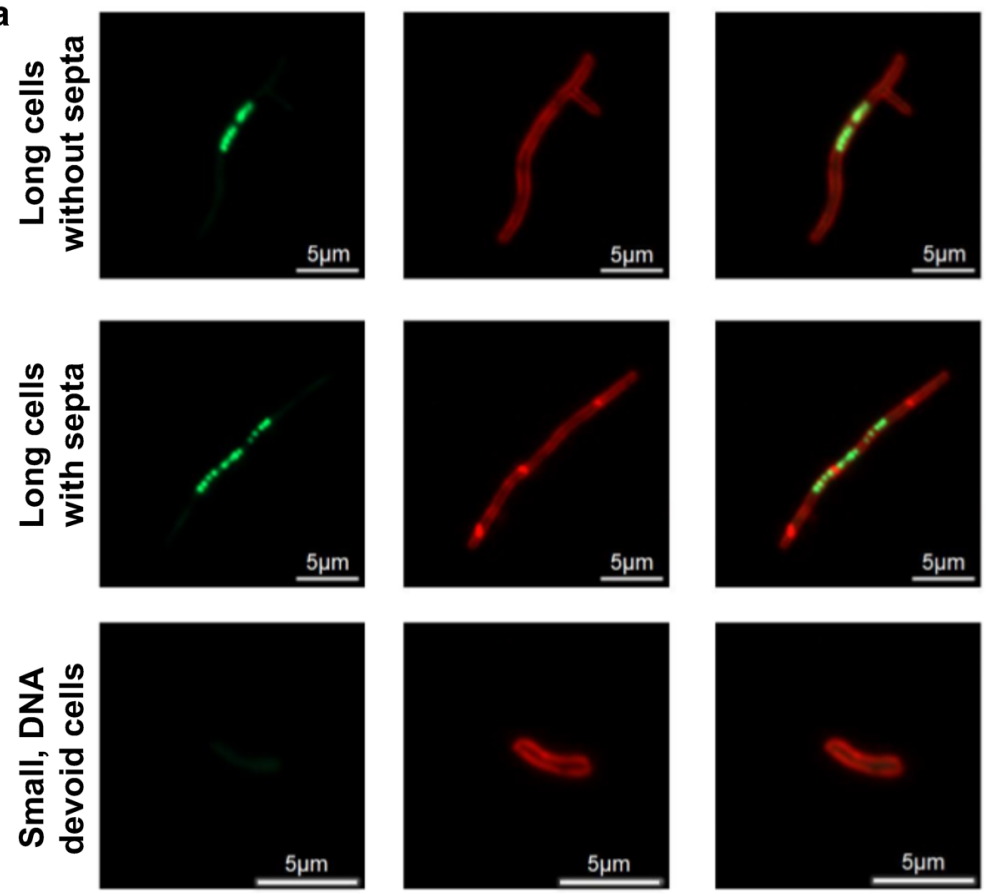

DNA stain

(SYTO 24)

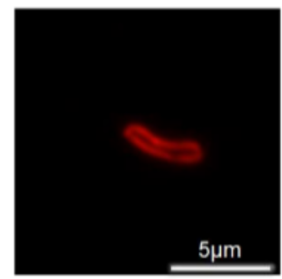

Membrane stain (FM4-64FX)
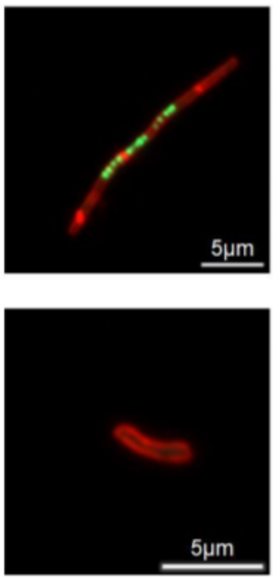

Overlay

b

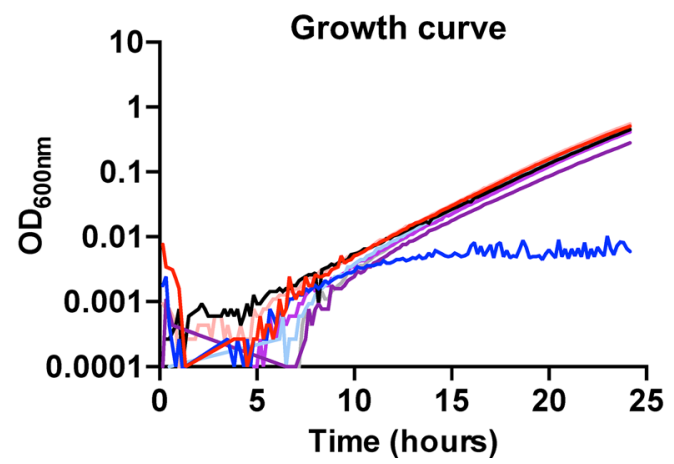

- mamA KD no ATc

- $\operatorname{mamAKD}+\mathrm{ATc}$

- Nonspecific sgRNA no ATc

- Nonspecific sgRNA + ATc

— mamA KD $\triangle M S M E G \_3214$ no ATc

— mamA KD $\triangle M S M E G \quad 3214$ + ATC

— Nonspecific sgRNA $\triangle M S M E G \_3214$ no ATc

— Nonspecific sgRNA $\triangle M S M E G \_3214$ + ATc

Fig. 3 Morphologies of mamA depleted cells and rescue by deletion of MSMEG_3214. a Microscopy of the mamA KD strain treated with ATc for 12 h. Cells were stained with SYTO 24 (green) and FM 4-64FX (red) to visualize DNA and membranes, respectively. The images represent cells of three major phenotypic groups observed. The left column shows DNA stained only, the center column shows membrane stained only, and the right column shows the merged fluorescent images. b Strains with depleted mamA (mamA KD), nonspecific CRISPRi control with an sgRNA sequence that does not target any specific part of M. smegmatis genome (Nonspecific sgRNA), mamA KD in an MSMEG_3214-deleted background (mamA KD

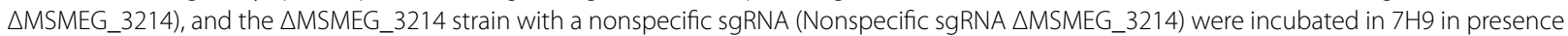
(+) or in absence of ATc to activate or not the CRISPRi knockdown system, respectively

\section{Discussion}

M. smegmatis is a widely used non-pathogenic model for $M$. tuberculosis. These species share numerous orthologous genes, but in most cases there is no experimental determination of whether orthologous genes pairs have equivalent functions in both organisms. While M. tuberculosis MamA is a DNA methyltransferase that affects gene expression during normal growth and supports survival in hypoxia [5], here we provide evidence that the orthologous methyltransferase in M. smegmatis is part of an R-M system. Although the catalytic activity of MamA in both 
species is DNA methylation, they have different biological functions, which may reflect different evolutionary pathways. Notably, M. tuberculosis is an obligate lung pathogen, and as such does not likely come into frequent contact with phages. Selective pressure for maintenance of R-M systems may therefore be reduced. Consistent with this, a type I R-M system (HsdM/ HsdS) in M. tuberculosis is missing the cognate restriction enzyme. The different sequence specificities of MamA in M. tuberculosis and M. smegmatis $[5,19]$ also highlight their evolutionary and functional divergence. Interestingly, multiple $M$. tuberculosis sub-lineages have MamA mutations that cause complete or partial loss of function $[5,9,20,21]$.

A BLAST search against the NCBI database performed in our laboratory revealed that while MamA orthologs are present in most mycobacteria, MSMEG_3214 orthologs are absent from the most prominent pathogenic species including $M$. tuberculosis, M. avium complex, M. leprae, $M$. abscessus, M. marinum, and M. kansasii. Some fast-growing mycobacteria capable of causing disease do encode MSMEG_3214 orthologs; for example, M. fortuitum, M. peregrinum, and M. goodii.

This work provides evidence for the first time that an active R-M system is present in M. smegmatis. Further experiments need to be done to confirm the recognition of CTCGAG palindromic sequence by both $M$. smegmatis MamA methyltransferase and MSMEG_3214 endonuclease as predicted by REBASE database.

\section{Limitations}

- The levels of mamA transcript in the mamA KD relative to WT strain were not determined.

- Microscopy of strain mamA KD-DMSMEG_3214 was not performed.

- Enzymatic activities of MamA and MSMEG_3214 were not determined, and DNA methylation status was not measured.

\begin{abstract}
Abbreviations
R-M system: Restriction-modification system; ATc: Anhydrotetracycline; KD: Knockdown; DIC microscopy: Differential interference contrast microscopy; CRISPRi: Clustered regularly interspaced short palindromic repeats interference; PAM: Protospacer adjacent motif; CFUs: Colony-forming units; OD: Optical density.
\end{abstract}

\section{Acknowledgements}

We thank members of the Shell lab for technical assistance and helpful discussions.

\section{Authors' contributions}

SER, YZ, SRJ and SSS conceived and designed the experiments. SER, YZ and SRJ performed the experiments. SER, MCM, and SSS analyzed the data. MCM and SSS wrote the manuscript. All authors read and approved the final manuscript.

\section{Funding}

This work was supported in part by NSF CAREER award 1652756 to SS.

\section{Availability of data and materials}

All the data supporting the findings is contained within the manuscript.

Ethics approval and consent to participate

Not applicable.

Consent for publication

Not applicable.

\section{Competing interests}

The authors declare that the research was conducted in the absence of any commercial or financial relationships that could be construed as a potential conflict of interest.

\section{Author details}

1 Department of Biology \& Biotechnology, Worcester Polytechnic Institute, Worcester, MA, USA. ${ }^{2}$ Program in Bioinformatics \& Computational Biology, Worcester Polytechnic Institute, Worcester, MA, USA.

Received: 29 May 2020 Accepted: 22 September 2020

Published online: 29 September 2020

\section{References}

1. Jeltsch A. Maintenance of species identity and controlling speciation of bacteria: a new function for restriction/modification systems? Gene. 2003;317:13-6

2. Asakura Y, Kobayashi I. From damaged genome to cell surface: transcriptome changes during bacterial cell death triggered by loss of a restriction-modification gene complex. Nucleic Acids Res. 2009;37(9):3021-31.

3. Asakura Y, Kojima H, Kobayashi I. Evolutionary genome engineering using a restriction-modification system. Nucleic Acids Res. 2011;39(20):9034-46.

4. Chang S, Cohen SN. In vivo site-specific genetic recombination promoted by the EcoRl restriction endonuclease. Proc Natl Acad Sci. 1977;74(11):4811-5

5. Shell SS, Prestwich EG, Baek S-H, Shah RR, Sassetti CM, Dedon PC, et al. DNA methylation impacts gene expression and ensures hypoxic survival of Mycobacterium tuberculosis. PLoS Pathog. 2013. 9(7).

6. Sassetti CM, Rubin EJ. Genetic requirements for mycobacterial survival during infection. Proc Natl Acad Sci. 2003;100(22):12989-94.

7. DeJesus MA, Gerrick ER, Xu W, Park SW, Long JE, Boutte CC, et al. Comprehensive essentiality analysis of the Mycobacterium tuberculosis genome via saturating transposon mutagenesis. MBio. 2017;8(1):e02133-16.

8. Sassetti CM, Boyd DH, Rubin EJ. Genes required for mycobacterial growth defined by high density mutagenesis. Mol Microbiol. 2003;48(1):77-84.

9. Gomez-Gonzalez PJ, Andreu N, Phelan JE, de Sessions PF, Glynn JR, Crampin AC, et al. An integrated whole genome analysis of Mycobacterium tuberculosis reveals insights into relationship between its genome, transcriptome and methylome. Sci Rep. 2019;9(1):1-11.

10. De Wet TJ, Gobe I, Mhlanga MM, Warner DF. CRISPRi-Seq for the Identification and Characterisation of Essential Mycobacterial Genes and Transcriptional Units. BioRxiv. 2018. 358275

11. Rock JM, Hopkins FF, Chavez A, Diallo M, Chase MR, Gerrick ER, et al. Programmable transcriptional repression in mycobacteria using an orthogonal CRISPR interference platform. Nat Microbiol. 2017;2(4):1-9.

12. Morris P, Marinelli LJ, Jacobs-Sera D, Hendrix RW, Hatfull GF. Genomic characterization of mycobacteriophage Giles: evidence for phage acquisition of host DNA by illegitimate recombination. J Bacteriol. 2008;190(6):2172-82.

13. Murphy KC, Papavinasasundaram K, Sassetti CM. Mycobacterial recombineering. In: Mycobacteria Protocols. Springer; 2015. p. 177-99. 
14. Martini MC, Zhou Y, Sun H, Shell SS. Defining the transcriptional and post-transcriptional landscapes of Mycobacterium smegmatis in aerobic growth and hypoxia. Front Microbiol. 2019;10:591.

15. Mann KM, Huang DL, Hooppaw AJ, Logsdon MM, Richardson K, Lee $\mathrm{HJ}$, et al. Rv0004 is a new essential member of the mycobacterial DNA replication machinery. PLoS Genet. 2017;13(11):e1007115.

16. Wilkowska K, Mruk I, Furmanek-Blaszk B, Sektas M. Low level expression of the Type II restriction-modification system confers potent bacteriophage resistance in Escherichia coli. DNA Res. 2020;

17. Mruk I, Kaczorowski T, Witczak A. Natural tuning of restriction endonuclease synthesis by cluster of rare arginine codons. Sci Rep. 2019;9(1):1-13.

18. Takahashi N, Naito Y, Handa N, Kobayashi I. A DNA methyltransferase can protect the genome from postdisturbance attack by a restriction-modification gene complex. J Bacteriol. 2002;184(22):6100-8.

19. Roberts RJ, Vincze T, Posfai J, Macelis D. REBASE - a database for DNA restriction and modification: enzymes, genes and genomes. Nucleic Acids Res. 2015;43(D1):D298-9.
20. Phelan J, de Sessions PF, Tientcheu L, Perdigao J, Machado D, Hasan R, et al. Methylation in Mycobacterium tuberculosis is lineage specific with associated mutations present globally. Sci Rep. 2018;8(1):1-7.

21. Zhu L, Zhong J, Jia X, Liu G, Kang Y, Dong M, et al. Precision methylome characterization of Mycobacterium tuberculosis complex (MTBC) using PacBio single-molecule real-time (SMRT) technology. Nucleic Acids Res. 2016;44(2):730-43.

\section{Publisher's Note}

Springer Nature remains neutral with regard to jurisdictional claims in published maps and institutional affiliations.
Ready to submit your research? Choose BMC and benefit from:

- fast, convenient online submission

- thorough peer review by experienced researchers in your field

- rapid publication on acceptance

- support for research data, including large and complex data types

- gold Open Access which fosters wider collaboration and increased citations

- maximum visibility for your research: over $100 \mathrm{M}$ website views per year

At BMC, research is always in progress.

Learn more biomedcentral.com/submissions 